\title{
Evaluation of Mercury Exposure Reduction through a Fish Consumption Advisory Program for Anishinaabe Tribal Members in Northern Wisconsin, Michigan, and Minnesota
}

\author{
J. A. Foran, ${ }^{1}$ A. D. DeWeese, ${ }^{2}$ M. J. Hudson, ${ }^{3}$ and N. E. Kmiecik ${ }^{4}$ \\ ${ }^{1}$ EHSI, LLC, Whitefish Bay, 5005 N. Palisades Rd., WI 53217, USA \\ ${ }^{2}$ Wisconsin Department of Natural Resources, Madison, WI 53707, USA \\ ${ }^{3}$ Bad River Watershed Association, Ashland, WI 54806, USA \\ ${ }^{4}$ Great Lakes Indian Fish and Wildlife Commission, Odanah, WI 54861, USA \\ Correspondence should be addressed to J. A. Foran, jforan@ehsillc.com \\ Received 19 November 2009; Revised 28 April 2010; Accepted 19 June 2010 \\ Academic Editor: Karen Glanz
}

Copyright (๑) 2010 J. A. Foran et al. This is an open access article distributed under the Creative Commons Attribution License, which permits unrestricted use, distribution, and reproduction in any medium, provided the original work is properly cited.

\begin{abstract}
The Great Lakes Indian Fish and Wildlife Commission has an extensive program to inform Anishinaabe tribal members from northern Wisconsin, Michigan, and Minnesota who harvest and consume walleye about the health risks of consuming these fish, and to encourage harvest and consumption practices that reduce exposure to MeHg. We report here the results of a probabilistic analysis of exposure to methyl mercury $(\mathrm{MeHg}$ ) among tribal members who consume walleye. The model predicts that the potential for greatest exposures to $\mathrm{MeHg}$ occur among women of child-bearing age and children who consume large walleye from lakes that contain heavily contaminated ( $\mathrm{MeHg}$ concentration $>0.5 \mathrm{mg} / \mathrm{kg}$ ) fish. The analysis allows GLIFWC to evaluate, focus, and fine-tune its initiatives to protect the health of tribal members in ways that result in exposure and risk reduction for tribal harvesters, women of child-bearing age, and children, while maintaining important tribal lifeways, which include the harvest and consumption of walleye.
\end{abstract}

\section{Introduction}

The effects of exposure to low levels of methyl mercury $(\mathrm{MeHg})$ are well documented and include developmental deficits, particularly in children exposed prenatally $[1,2]$. A significant source of $\mathrm{MeHg}$ in the US diet is the consumption of contaminated fish, and in 2004 the USFDA and USEPA issued a joint announcement advising women of childbearing age, pregnant women, and young children to avoid consumption of shark, swordfish, tilefish, and mackerel, and to limit the consumption of albacore tuna [3]. Many sport or subsistence-caught freshwater fish species also contain elevated levels of $\mathrm{MeHg}$ and, as a result, state and tribal organizations in the Great Lakes basin and elsewhere issue advice to reduce or avoid consumption of these fish [4-9].

Native Americans often consume greater quantities of freshwater fish than the general public [10] and, therefore, may be exposed to higher levels of MeHg. Anishinaabe
(Ojibwe or Chippewa) in the Great Lakes region (hereaftertribal members), including those who belong to tribes that are members of the Great Lakes Indian Fish and Wildlife Commission (GLIFWC), harvest and consume freshwater fish as part of their traditional lifeways, an approach to living that incorporates culture, spirituality, language, and traditions including consumption of indigenous foods. Historically, fish comprised $17-38 \%$ of the traditional diet of Anishinaabe in Northern Wisconsin [11]. Walleye (Sander vitreus), a top predator that has elevated tissue concentrations of $\mathrm{MeHg}$, is the species most frequently harvested and consumed by tribal members. Most walleye harvesting and associated consumption occur in the spring of the year following ice-out conditions on inland lakes. In spring 2006, approximately 75,800 adult walleye were harvested from 191 inland lakes in the 1837 and 1842 ceded territories of Michigan, Minnesota, and Wisconsin [12-14]. Because of harvest and consumption characteristics, tribal members in 
the Northern Great Lakes region may be exposed to elevated concentrations of $\mathrm{MeHg}$ and, as a result, GLIFWC issues advice that encourages behavior that reduces exposure to $\mathrm{MeHg}$ associated with harvest and consumption of walleye [9].

GLIFWC develops and disseminates lake-specific, riskbased, culturally sensitive walleye consumption advice via color-coded maps $[9,15]$. Color codes correspond with walleye consumption advice (Table 1), with lakes coded blue associated with the least restrictive advice (eat up to 8 meals/month) and red lakes associated with the most restrictive advice (do-not-eat). Advice categories are chosen based on the goals of protecting the health of tribal members (reducing mercury exposure) and preserving tribal lifeways (walleye harvest and consumption). Each advice category constrains consumption of contaminated walleye to levels that limit mercury exposure to the US EPA reference dose (RfD) for methyl mercury. Eight versions of the advisory maps are prepared, one for each of the six GLIFWC-member tribes in Wisconsin, a seventh for select lakes in Minnesota, and the eighth for select lakes in Michigan.

From 1997 to 2002, GLIFWC conducted a survey to determine fish consumption rates and patterns of tribal members in northern Minnesota, Michigan, and Wisconsin [9]. Consumption data from the survey were combined with data on tribal harvest levels and concentrations of $\mathrm{MeHg}$ in harvested fish tissue [15] to model the exposure to $\mathrm{MeHg}$ via consumption of contaminated walleye among tribal members. We report here the results of the analysis of $\mathrm{MeHg}$ exposure among a group of fish consumers from GLIFWC-member tribes. The results are used to assess GLIFWC's efforts to reduce mercury exposure and health risks associated with consumption of contaminated walleye in ways that maintain the important tribal lifeways of walleye harvest and consumption [9].

\section{Methods}

The objective of the exposure analysis was to identify subgroups of the tribal population with potential for the highest exposures to $\mathrm{MeHg}$ from their walleye consumption patterns, and to assess the impact of risk mitigation advice on exposure and risk reduction. Particular emphasis in this study was focused on gender- and age-specific exposure profiles.

Fish consumption profiles for each gender (male/female) and four age groups (children aged 1-5 years, children aged 6-14 years, women of child-bearing age, and males older than 14 years and females beyond child bearing age) were created from the GLIFWC fish consumption survey (described below and in [9]) using the LifeLine Dietary Record Generator (DRG). The probability that an individual (of a given gender and age) consumed walleye on a given day (including 0 or no fish consumption) and the intake when walleye were consumed were estimated from the fish consumption survey.

The DRG constructs a file of age- and gender-specific dietary records reflecting individual walleye consumption, which serves as the basis for the fish intake parameter of the exposure algorithm; one of the two parameters imported into the exposure/risk assessment software (Customized Dietary Assessment Software-CDAS). Multiyear, multi-site concentrations of $\mathrm{MeHg}$ in walleye tissue, the second parameter imported into the CDAS, were arranged into a series of residue concentration distributions, each representing a different lake color code (described below) and fish size category.

The dietary intake profiles and distributions of $\mathrm{MeHg}$ concentrations in walleye tissue were brought together in the CDAS to yield a series of exposure assessments, each representing a different scenario of lake color code and fish size category. The software utilizes a probabilistic approach, drawing a walleye intake value for each "simulated" person (defined by age and gender) and a $\mathrm{MeHg}$ concentration value from the residue distribution. Ten thousand iterations were run for each simulated person. The resultant exposure distribution provides the median and 95th percentile exposure values (among others) for selected age/gender groups and can be reported for various lake color code/fish size scenarios. The interindividual exposure variation is captured in the distribution of these 10,000 iterations.

Changes to the dietary profiles by age and gender resulting from mitigation options (fish consumption advice) were captured in the Dietary Record Generator by creating new dietary records for each mitigation option. Mitigation options addressing the potential residues of $\mathrm{MeHg}$ in the consumed fish were reflected by selection of residue concentration distributions from lake color code or fish size categories. The exposure assessments were then rerun using these consumption and residue data files modified as a result of mitigation options.

2.1. Walleye Consumption. Walleye consumption data were drawn from a survey of tribal fish consumption conducted by GLIFWC from 1997 to 2002 (additional details of the consumption study are provided in [9] ). Fifty-one families, nearly all of which included children under the age of 15, from 10 tribes, recorded their fish consumption in food diaries during the study. Nine to twelve families participated each year, and three families participated during two study years. One family member recorded each participating family member's meals of harvested fish eaten at home over the course of a study year. Meal frequency information was collected for eight months during year 1 (April 1, 1997-November 30, 1997); thus, year 1 data were used in calculations of spring but not annual consumption rates. Fish consumption information, including meal frequency, was collected for 12 months during years $2-5$, and these data were used in calculations of seasonal and annual consumption rates and meal size.

Consumption rates reported here and used in the probabilistic analysis reflect at-home consumption of walleye, but not other fish or fish purchased or consumed away from home (e.g., at restaurants or tribal ceremonies); thus, total fish consumption rates among tribal members are higher. Of the 1699 meal records of harvested walleye eaten at home, $114(6.7 \%)$ were meals of walleye mixed with another species. In these cases, we limited the analysis to walleye by dividing 
TABLE 1: Percent of lakes with walleye meal frequency categories for the sensitive (women of child-bearing age and children under the age of 15 years) and general (all others) populations.

\begin{tabular}{lccc}
\hline Advice category & Lake color code & \multicolumn{2}{c}{$\begin{array}{c}\text { Percent of lakes in each advice category } \\
\text { General population }\end{array}$} \\
\hline 8 meals/month & Blue & $0.3 \%$ & $17.7 \%$ \\
4 meals/month & Green & $2.7 \%$ & $52.9 \%$ \\
2 meals/month & Yellow & $24.6 \%$ & $28.7 \%$ \\
1 meal/month & Orange & $54.6 \%$ & $0.7 \%$ \\
Do not eat & Red & $17.8 \%$ & $0.0 \%$ \\
\hline
\end{tabular}

the total grams eaten by the number of species reported for the meal. Approximately 3\% of recorded meals contained no meal weight information. A participant's average meal weight was used in these instances.

The frequency of walleye meals consumed by each participant was determined from the consumption survey for spring (April through June-91 days), summer (July through September - 92 days), fall (October through December-92 days), and winter (January through March-90 days). Each participant's seasonal meal frequency was divided by the number of days in each season to obtain the daily probability of consuming walleye in each season.

Consumption probabilities/frequencies and portion sizes were calculated and entered directly into the LifeLine software for the corresponding age and season without data fitting or other alterations. While average consumption rates reported below provide a summary of consumption behavior, we analyzed, via LifeLine, the entire range of data to preserve and more closely represent actual consumption habits of tribal members. By preserving the actual pattern of consumption among tribal members instead of using average rates, it is possible to investigate the effect of different consumption patterns upon the exposure profile of an entire community. Tribal members consuming small or large amounts of walleye as well as those consuming walleye more or less frequently are visualized by this technique.

\subsection{Methyl Mercury Concentrations in Walleye Tissue.} GLIFWC has a database of 4,555 samples of lake- and size-specific fish tissue concentrations of $\mathrm{MeHg}$ generated over 19 years (including years when the fish consumption survey was conducted) from 224 lakes in the 1837 and 1842 ceded territories of Wisconsin, Michigan, and Minnesota. GLIFWC has combined these data with walleye tissue analyses conducted by state agencies and has developed fish consumption advice for 293 lakes in the ceded territories, 207 of which are harvested by tribal members, following Madsen et al. [15] and as described below.

Lake-specific $\mathrm{MeHg}$ concentrations in walleye tissue and walleye lengths were log transformed and used to develop regressions $(\ln \mathrm{MeHg}=$ slope $*$ Length + intercept) for the 293 lakes with consumption advice developed by GLIFWC [15]. Lake-specific regression equations were applied to individual walleye lengths from each of the 207 lakes harvested by tribal members between 2005 and 2007 to obtain predicted $\mathrm{MeHg}$ concentrations for all harvested walleye. Eight predicted concentrations from this analysis exceeded the maximum $\mathrm{MeHg}$ concentration in the GLIFWC sampling database $(3.10 \mathrm{mg} / \mathrm{kg}$ wet weight). While walleye with mercury concentrations greater than $3.10 \mathrm{mg} / \mathrm{kg}$ likely exist in some lakes, we capped the predicted concentration in the probabilistic analysis at $3.10 \mathrm{mg} / \mathrm{kg}$ to avoid overestimating mercury exposure. To account for different harvest levels from each lake, a distribution of predicted $\mathrm{MeHg}$ concentrations was developed and weighted based on the proportion of total annual harvest from each lake. The resulting distributions were entered as residue files in the LifeLine software.

GLIFWC analyzes, and tribal members typically consume, skin-off walleye fillets. However, tissue concentration data provided by state agencies and included in the GLIFWC database are drawn from skin-on walleye samples, which are approximately $16 \%$ lower than skin-off concentrations [16]; therefore, we converted all skin-on concentrations of $\mathrm{MeHg}$ to skin-off concentrations by multiplying skin-on concentrations by a factor of 1.16 .

2.3. Exposure Analysis. Probabilistic estimates of $\mathrm{MeHg}$ exposure were developed for three scenarios: (a) walleye harvested and consumed from all lakes regardless of lake color codes included on GLIFWC advisory maps (described below and in [9] ), (b) walleye harvested and consumed from color-coded red lakes (do-not-eat consumption advice), and (c) lakes with color codes other than red-restricted consumption advice. Methyl mercury exposure was evaluated in each scenario for walleye smaller than $41 \mathrm{~cm}$ (about 16 inches), walleye larger than $41 \mathrm{~cm}$, walleye smaller than 51 $\mathrm{cm}$ (about 20 inches), and walleye larger than $51 \mathrm{~cm}$. Output was analyzed using SAS [17] system for Windows version 6.12 to provide exposure estimates for age-sex groupings beyond those available in the Lifeline software. Probabilistic estimates of MeHg exposure were compared with the US EPA [18] reference dose $(0.1 \mathrm{ug} / \mathrm{kg} /$ day $)$ to provide a qualitative (or semiquantitative) expression of risk.

\section{Results and Discussion}

3.1. Methyl Mercury Concentrations in Walleye Tissue. Concentrations of $\mathrm{MeHg}$ in tissues of walleye are as high as $3.10 \mathrm{mg} / \mathrm{kg}$ wet weight with the greatest concentrations generally occurring in larger fish (Table 2). Walleye consumption advice is developed by GLIFWC for individual lakes based 
TABLE 2: Methyl mercury concentrations in walleye $(n=221,960)$ from lakes for which GLIFWC issues consumption advice (see DeWeese et al. 2009 [9] for a description of lake codes and advice categories).

\begin{tabular}{|c|c|c|c|c|c|}
\hline \multirow{2}{*}{ Lake Color } & \multirow{2}{*}{ Walleye Size $(\mathrm{cm})$} & \multicolumn{4}{|c|}{ Tissue Concenration (mg/kg) } \\
\hline & & Median & 95th \% & 99th \% & Max. \\
\hline ALL & $<41$ & 0.11 & 0.40 & 0.51 & 0.91 \\
\hline ALL & $\geq 41$ & 0.22 & 0.62 & 0.95 & 3.10 \\
\hline ALL & $<51$ & 0.15 & 0.43 & 0.62 & 1.27 \\
\hline ALL & $\geq 51$ & 0.28 & 0.88 & 1.35 & 3.10 \\
\hline ALL & ALL & 0.17 & 0.47 & 0.73 & 3.10 \\
\hline RED & $<41$ & 0.40 & 0.68 & 0.75 & 0.91 \\
\hline RED & $\geq 41$ & 0.61 & 1.09 & 1.87 & 3.10 \\
\hline RED & $<51$ & 0.43 & 0.74 & 0.89 & 1.27 \\
\hline RED & $\geq 51$ & 0.94 & 2.08 & 2.73 & 3.10 \\
\hline RED & ALL & 0.44 & 0.80 & 1.11 & 3.10 \\
\hline OR & $<41$ & 0.11 & 0.31 & 0.45 & 0.71 \\
\hline OR & $\geq 41$ & 0.21 & 0.55 & 0.84 & 3.10 \\
\hline OR & $<51$ & 0.14 & 0.36 & 0.51 & 0.81 \\
\hline OR & $\geq 51$ & 0.28 & 0.80 & 1.20 & 3.10 \\
\hline OR & ALL & 0.16 & 0.41 & 0.60 & 3.10 \\
\hline
\end{tabular}

All: walleye harvested from all lakes for which GLIFWC issues consumption advice.

Red: walleye harvested from lakes color-coded red (those for which GLIFWC issues do-not-eat advice)

OR: walleye harvested from lakes color-coded other than red (lakes with consumption advice less restrictive than do-not-eat).

TABLe 3: Walleye Harvest Data, 2005-2007.

\begin{tabular}{lc}
\hline Total Walleye Harvested & 221,960 \\
Walleye with Length Information & 120,836 \\
Min Length $(\mathrm{cm})$ & 16.0 \\
Max Length $(\mathrm{cm})$ & 86.1 \\
Mean Length $(\mathrm{cm})$ & 41.1 \\
Median Length $(\mathrm{cm})$ & 40.1 \\
95th\% Length $(\mathrm{cm})$ & 56.1 \\
\hline
\end{tabular}

on size- and lake-specific concentrations of $\mathrm{MeHg}$ in walleye tissue. The goal of GLIFWC's advisory program is to encourage harvest and consumption of walleye while minimizing exposure to MeHg. Consumption advice is based on $\mathrm{MeHg}$ concentrations in tissues of a $51-\mathrm{cm}$ (20 inch) walleye [15], although GLIFWC encourages consumption of smaller fish; therefore, we conducted the probabilistic exposure analysis for walleye larger and smaller than $51 \mathrm{~cm}$ as well as fish larger and smaller than $41 \mathrm{~cm}$ (16 inches), the mean length of all harvested walleye (Table 3 ).

3.2. Walleye Consumption. Participants in the GLIFWC fish consumption survey consumed harvested walleye at-home at a mean rate of $5.6 \mathrm{~g} /$ day (95th percentile $18.0 \mathrm{~g} /$ day). At-home walleye consumption rates were greater for males aged 15 years and older (mean $9.1 \mathrm{~g} /$ day, 95th percentile $36.3 \mathrm{~g} /$ day) than for the other age-sex groups. There was an annual pattern of at-home harvested walleye consumption, with peak rates for participants occurring in the spring concurrent with and following the annual harvest. The mean athome harvested walleye consumption rate during this period was $10.1 \mathrm{~g} /$ day (95th percentile—29.7 g/day). Males aged 15 years and older had the highest at-home consumption rate of harvested walleye during spring (mean-15.0 g/day, 95th percentile- $49.2 \mathrm{~g} /$ day). Walleye consumption rates for all groups were lower in periods other than spring [9].

3.3. $\mathrm{MeHg}$ Exposure. GLIFWC evaluated the efficacy of its advisory program [9] and found that it increased awareness of advisory maps among Wisconsin, Michigan, and Minnesota harvesters as well as among women of childbearing age in Wisconsin (the only state where that group was assessed). The program also resulted in an increase in the percentage of tribal harvesters who preferred smaller walleye (with lower mercury concentrations), although a similar behavioral change did not occur among women of childbearing age in Wisconsin. Concurrent with these behavioral changes was an increase in tribal walleye harvest, indicating that the advisory program did not adversely affect this important tribal lifeway [9]. However, we did not determine directly whether changes in consumption behavior and $\mathrm{MeHg}$ exposure were influenced by the advisory process since the source-lake color codes, walleye length, and $\mathrm{MeHg}$ concentrations were not determined for walleye consumed by individuals participating in the consumption survey. Therefore, we modeled $\mathrm{MeHg}$ exposure of tribal members who participated in the GLIFWC fish consumption survey by assuming that participants consumed walleye from size distributions similar to the harvest record for each lake depicted on GLIFWC advisory maps. This is appropriate, as walleye are harvested by tribal members, with few exceptions, from a defined (declared) set of lakes, and detailed harvest records are maintained by GLIFWC for these lakes.

Methyl mercury exposure among individuals participating in the consumption survey is a function of fish 


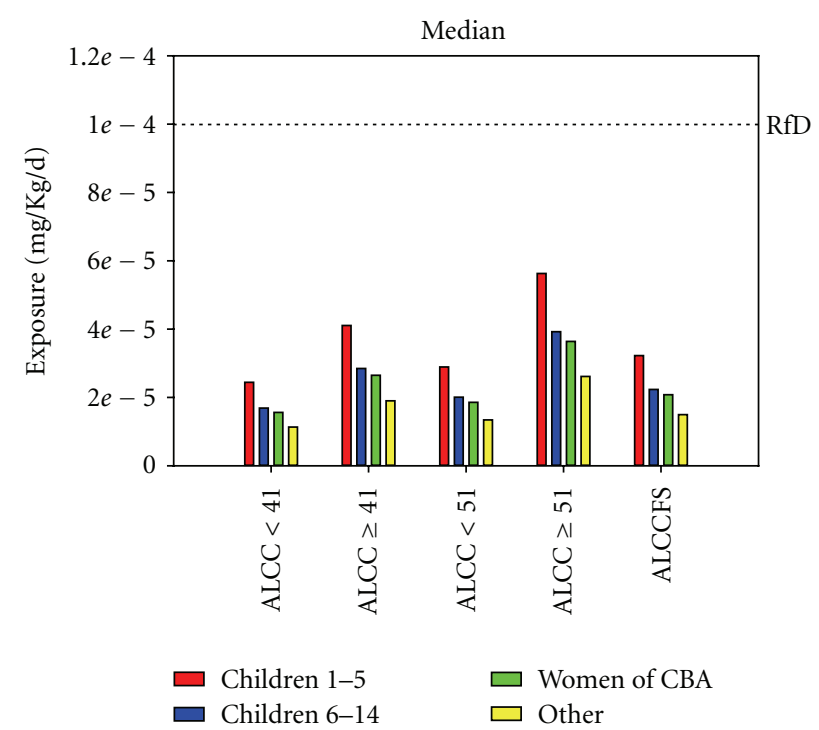

(a)

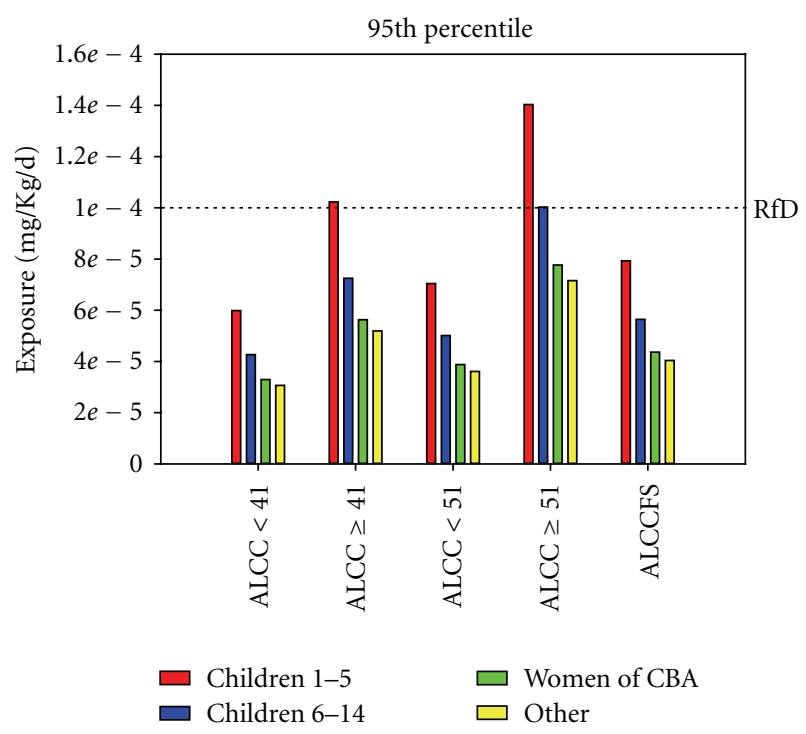

(b)

FIgURE 1: Median (a) and 95th percentile (b) exposure for all lakes/color codes, size. ALCC: all lakes, color codes; ALCCFS: all lakes, color codes, fish sizes; <41 (etc.): walleye length less than $41 \mathrm{~cm}$; RfD: reference dose for methyl mercury; other (yellow bars) include females beyond child-bearing age and males greater than age 14 years.

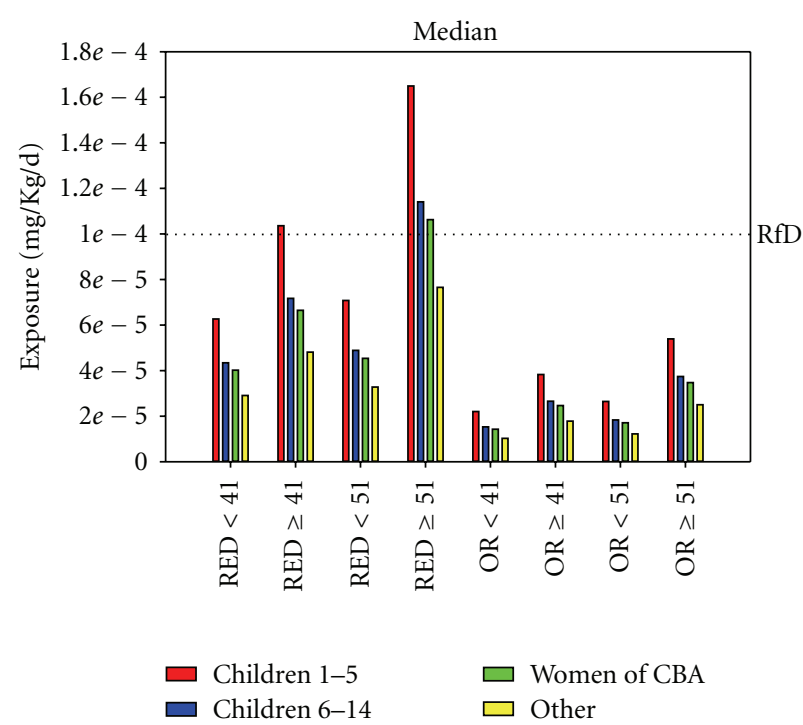

(a)

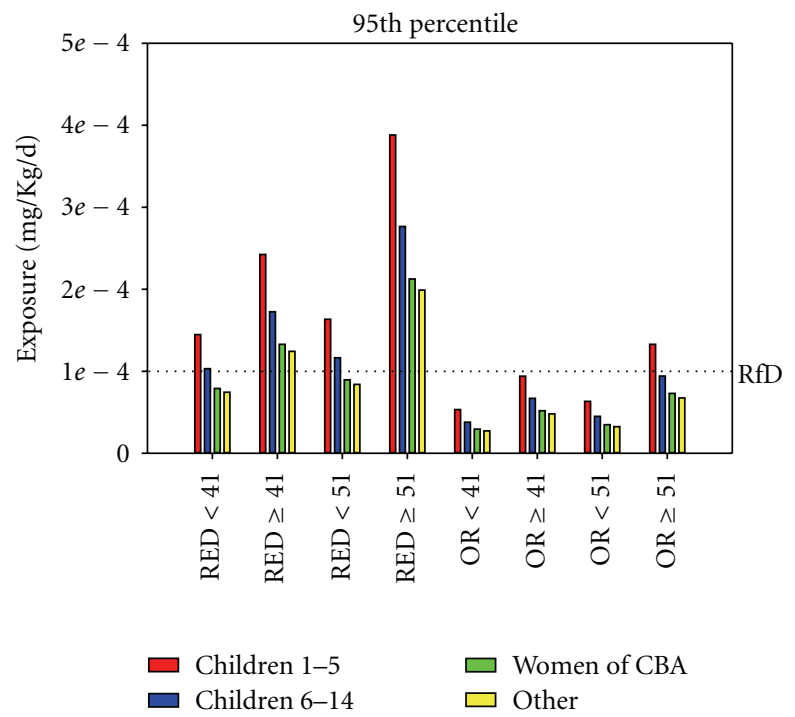

(b)

FIGURE 2: Median (a) and 95th percentile (b) exposure for consumption of fish harvested from color-coded red lakes (RED) and lakes colorcoded other than red (OR), and for walleye less or greater than 41 and $51 \mathrm{~cm}$. Other (yellow bars) include females beyond child-bearing age and males greater than age 14 years.

size and lakes from which consumed walleye are harvested. When walleye are consumed without regard to the source lake, median and 95th percentile $\mathrm{MeHg}$ exposures (Figures $1(\mathrm{a})$ and 1(b)) are greatest for all groups when fish of $51 \mathrm{~cm}$ (20 inches) or larger are consumed; however, median exposure levels are less than the mercury reference dose (RfD) for all individuals and fish's sizes, while 95th percentile exposures are greater than the mercury RfD for children aged 1-5 consuming only fish larger than $41 \mathrm{~cm}$ (16 inches,
Figures 1(a) and 1(b)). Median and 95th percentile $\mathrm{MeHg}$ exposure levels are greatest in young children aged $1-5$ and 6-14 years (Figures 1(a) and 1(b)), and lower in women of child-bearing age and "other" individuals (men beyond aged 15 and women beyond child-bearing age, Figures 1(a) and $1(\mathrm{~b})$ ).

Median and 95th percentile MeHg exposures are highest when larger walleye $(>51 \mathrm{~cm})$ harvested from lakes that are color-coded red are consumed, and lower when walleye 
under $41 \mathrm{~cm}$ from nonred lakes are consumed (Figures 2(a) and 2(b)). Consumption of walleye at rates observed in the survey would result in exposure levels that are highest for children and lower for women of child bearing age and other adults; however, median exposure levels (Figure 2(a)) would only exceed the mercury reference for children aged 1-5 years who consume walleye greater than $41 \mathrm{~cm}$ harvested from color-coded red lakes (lakes containing walleye with the greatest $\mathrm{MeHg}$ concentrations), and for children aged 614 years and women of child-bearing age who consume fish larger than $51 \mathrm{~cm}$ from lakes that are color-coded red. While $\mathrm{MeHg}$ exposure patterns at the 95th percentile are similar to patterns at median exposure levels, 95th percentile exposures exceed the reference dose for $\mathrm{MeHg}$ when children and adults consume fish greater than $41 \mathrm{~cm}$ from color-coded red lakes, when children aged $1-5$ and 6-14 years consume any fish from red lakes, and when children aged 1-5 consume fish greater than $51 \mathrm{~cm}$ (20 inches) from any lake (Figure 2(b)).

The probabilistic analysis provides important information about the influence of lake source and walleye size on potential $\mathrm{MeHg}$ exposure among subgroups of tribal members and reinforces GLIFWC's approach to developing and disseminating walleye consumption advice. For example, the potential for median $\mathrm{MeHg}$ exposure to exceed the mercury reference dose among children and women of child-bearing age who consume only larger fish from red lakes (Figure 2(a)) is of concern. GLIFWC has developed and disseminated walleye consumption advice for these individuals: to not eat walleye larger than $51 \mathrm{~cm}$ (20 inches), to not eat walleye from lakes color-coded red, and to consume smaller walleye from lakes other than those colorcoded red. The maps also encourage tribal members other than children and women of child-bearing age to eat fewer meals if they choose fish greater than $51 \mathrm{~cm}$ from any lake. Finally, the GLIFWC maps encourage tribal members to label and store walleye fillets so that consumption advice can be followed throughout the year by family members and others with whom walleye are shared.

This analysis enhances GLIFWC's ability to focus and fine-tune its initiatives to protect the health of tribal members who harvest and consume walleye through its fish consumption advisory program. More importantly, it supports GLIFWC's age- and gender-based approach to exposure and risk reduction initiatives for tribal members while maintaining important tribal lifeways that include the harvest and consumption of walleye.

\section{Acknowledgments}

The authors thank Chris Chaisson and Annie Chaisson for training on and assistance with application of the LifeLine software, Rick Madsen for his assistance in developing the residue distribution analysis, and the tribal members that participated in the fish consumption survey. The authors also thank two anonymous reviewers for helpful comments on earlier drafts of the paper. This paper was funded by grants from US government sources; however, it has not been subjected to agency peer and policy review and, therefore, does not necessarily reflect the views of the US government, and no official endorsement should be inferred. This paper was funded by The Agency for Toxic Substances and Disease Registry (ATSDR) Grant no. H75/ATH57008001 and by US Environmental Protection Agency, STAR Grant no. R831047.

\section{References}

[1] P. Grandjean, P. Weihe, R. F. White et al., "Cognitive deficit in 7-year-old children with prenatal exposure to methylmercury," Neurotoxicology and Teratology, vol. 19, no. 6, pp. 417428, 1997.

[2] NRC, Toxicological Effects of Methylmercury, National Research Council, National Academy Press, Washington, DC, USA, 2000.

[3] USEPA, "What you need to know about mercury in fish and shellfish," Report EPA-823-R-04-005, U.S. Environmental Protection Agency and U.S. Department of Health and Human Services, 2004, www.cfsan.fda.gov/ dms/admehg3.html.

[4] FDL, An Expectant Mothers Guide to Eating Minnesota and Fond $d u$ Lac fish, Fond du Lac Division of Resource Management, Cloquet, Minn, USA, 2001.

[5] MDCH, Michigan Family Fish Consumption Guide; Important Facts to Know If You Eat Michigan Fish, Michigan Department of Community Health, Lansing, Mich, USA, 2004.

[6] MDH, An Expectant Mother's Guide to Eating Minnesota Fish, Minnesota Department of Health, St. Paul, Minn, USA, 2004.

[7] WDHFS, A Woman's Guide to Eating Fish From Wisconsin, Wisconsin Department of Health and Family Services, Madison, Wis, USA, 2005.

[8] Chippewa Ottawa Resource Authority (CORA), A Family Guide to Eating Fish, CORA, Sault Ste. Marie, Mich, USA, 2006.

[9] A. D. Deweese, N. E. Kmiecik, E. D. Chiriboga, and J. A. Foran, "Efficacy of risk-based, culturally sensitive ogaa (walleye) consumption advice for anishinaabe tribal members in the Great Lakes Region," Risk Analysis, vol. 29, no. 5, pp. 729-742, 2009.

[10] NEJAC, "Fish consumption and environmental justice," Report, National Environmental Justice Advisory CouncilA Federal Advisory Committee to the U.S. EPA, Washington, DC, USA, 2002, http://www.epa.gov/compliance/ej/resources/ publications/nejac/fish-consump-report_1102.pdf.

[11] B. A. Smith, "From venison to salt pork: reconstructing the costs to Anishinabe families in 19th century Wisconsin," in Proceedings of the American Anthropological Association Annual Meeting, Chicago, Ill, USA, 2003.

[12] J. Krueger, "Spring 2006 Spearing by the Lac Vieux Desert Tribe," Memo to Jim Williams, Jr. and Don Klingman, 2006.

[13] J. Krueger, "Open water spearing in northern wisconsin by Chippewa Indians during 2006," Administrative Report 200702, Great Lakes Indian Fish and Wildlife Commission, 2007.

[14] N. Milroy and J. Krueger, "Open-water spearing and netting in the 1837 Minnesota ceded territory during the 20062007 quota year," Administrative Report 2008-07, Great Lakes Indian Fish and Wildlife Commission, 2008.

[15] E. R. Madsen, A. D. DeWeese, N. Kmiecik, J. A. Foran, and E. D. Chirboga, "Methods to develop consumption advice for mercury-contaminated walleye harvested by Ojibwe tribes in the 1837 and 1842 ceded territories of Michigan, Minnesota, and Wisconsin," Integrated Environmental Assessment and Management, vol. 14, no. 1, pp. 118-124, 2008. 
[16] E. R. Madsen and H. S. Stern, "Time trends of methylmercury in walleye in northern Wisconsin: a hierarchical bayesian analysis," Environmental Science and Technology, vol. 41, no. 13, pp. 4568-4573, 2007.

[17] SAS Institute, Step-By-Step Programming with Base SAS Software, SAS Institute, Cary, NC, USA, 2001.

[18] USEPA, Guidance for Assessing Chemical Contaminant Data for Use in Fish Advisories: Volume 2, Risk Assessment and Fish Consumption Limits, U.S. Environmental Protection Agency, Washington, DC, USA, 3rd edition, 2000, EPA 823-B-00-008. 


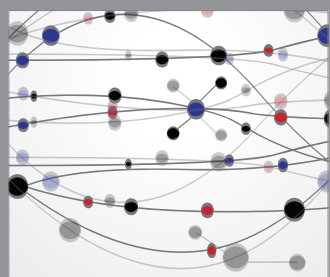

The Scientific World Journal
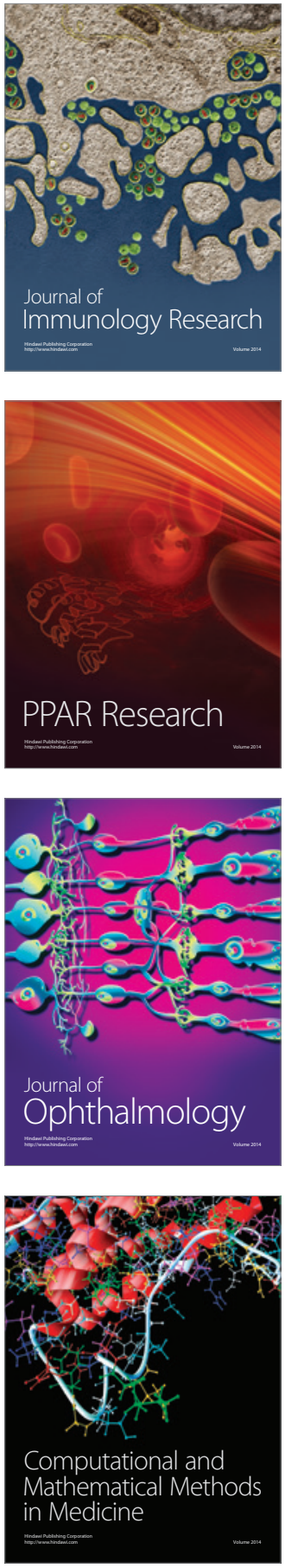

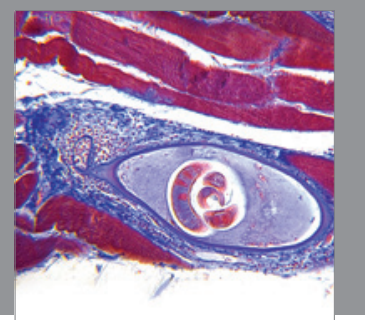

Gastroenterology

Research and Practice
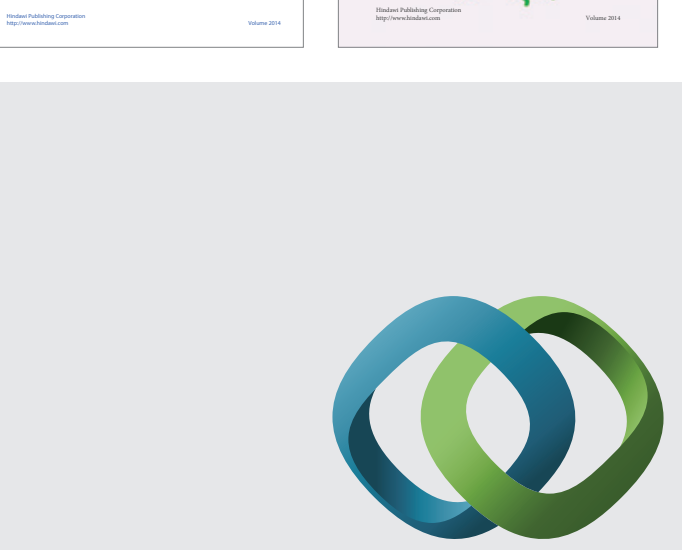

\section{Hindawi}

Submit your manuscripts at

http://www.hindawi.com
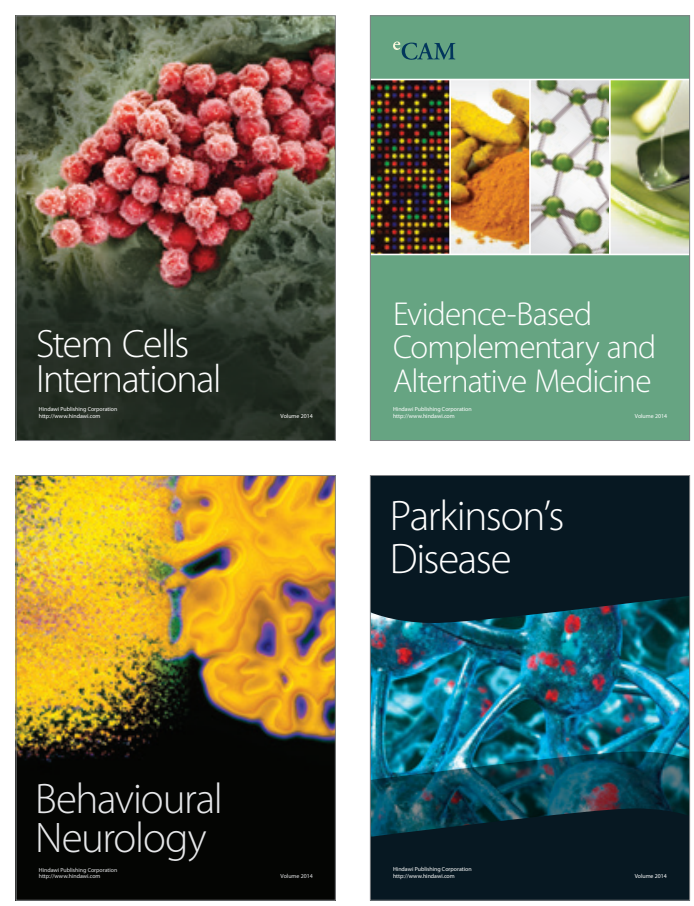

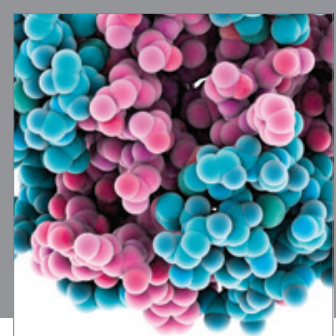

Journal of
Diabetes Research

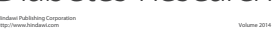

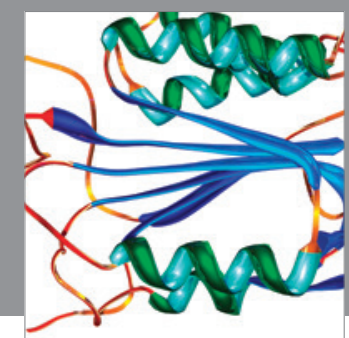

Disease Markers
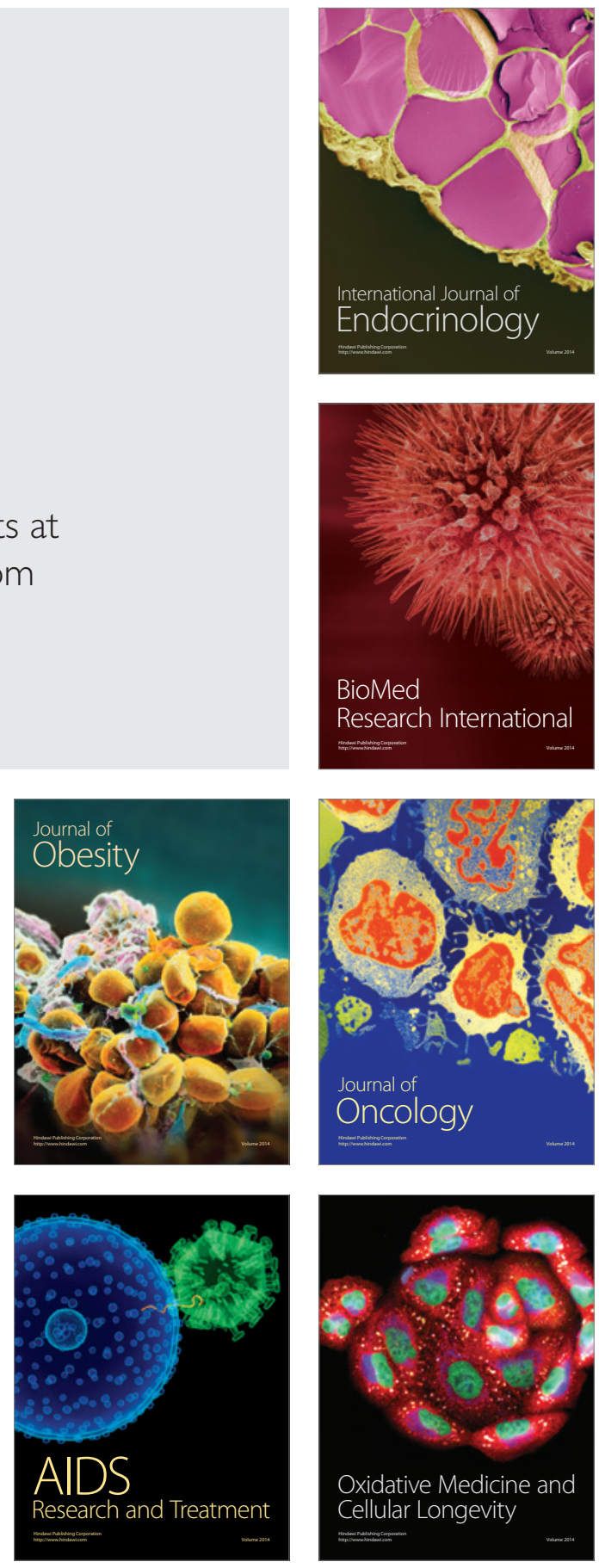